\title{
Processes and Variations in Digital Landscapes
}

\author{
Gareth Polmeer \\ Royal College of Art \\ Kensington Gore, London SW7 2EU, UK \\ contact@garethpolmeer.com
}

\section{INTRODUCTION}

In this presentation I screen a number of abstract video works where landscape and virtual space converge. I demonstrate the ways that systembased camera recordings are developed in postproduction around compositions of pixel, line and block structures. Developing a transient optics and digital aesthetic, the works reflect the human and technology in the relation to nature.

\section{FRAMES AND FLUX}

The works make the 'present' image from what is normally absent. The underlying structural principles of video frames and encoding are the bases of the developing picture. In this sense, the 'now' of a video image is multidimensional and variable; past, present and future are the simultaneous condition of a single moment (unlike film frames, which can be isolated as spatially and temporally distinct images).

In the works, video compression algorithms are not adapted in any way, but their predictive functions, colour elements and systems of lines, are made aesthetically apparent as questions of composition. Where film is the relation between frames, these videos explore immanent relations both in and between frames.

Questions of intervals and breaks have historically evolving contexts across the last century of the moving image, balanced by considerations of fluidity and flux. These have widely informed approaches to computer-based works; from the 1920s writings on interval and montage by Dziga Vertov and Sergei Eisenstein, and early abstract films of Viking Eggeling, to the single-frame structural experiments of Kurt Kren in the 1960s and experiments with the fluctuations of electronic signals in the work of Steina and Woody Vasulka in the 1970s.
It is in connections to such practices and ideas that some of the interests and contexts of my work have developed, creating an aesthetic from the possibilities of videographics, with emphasis on motion and forms developing in time, and the properties of colour and light.

\section{PROCESSES AND VARIATIONS}

The composite graphic below (Figure 1) shows an example set of frames developed around this varied body of work. Recorded footage, processed into linear arrangements is the basis for creating sequenced blocks of colour, where intervals and repetitions reveal patterns in time. In this regard, the works interrelate systems and approaches to painting, experimental film/video, and computer graphics. The works I present here have developed around high-definition video images of landscape, moving between degrees of figuration and abstraction (from works that resemble seascapes to pure colour fields).

In the first instance, the works develop variations of the same recording. These are layered into linear forms $1920 \times 1$ pixels in height and width, and are both temporally and spatially reorganised; firstly by iterations of the video frame rate $\left(1 / 25^{\text {th }}\right.$ of $a$ second) and secondly by ordered positions within the $1920 \times 1080$ frame area. Despite this systematic ordering, the images that emerge seem to have fluidity, and the continuities of movement and appearing natural forms are made by foregrounding discontinuous elements.

In the second instance, colour sampled from recordings is combined with the latter to form visual blurs between real and computer-generated imagery. Planes of colour shift the depths of the image, and the interplay of shapes and sequences foreground the forming image as the content. 


\section{Processes and variations in digital landscapes}

Gareth Polmeer
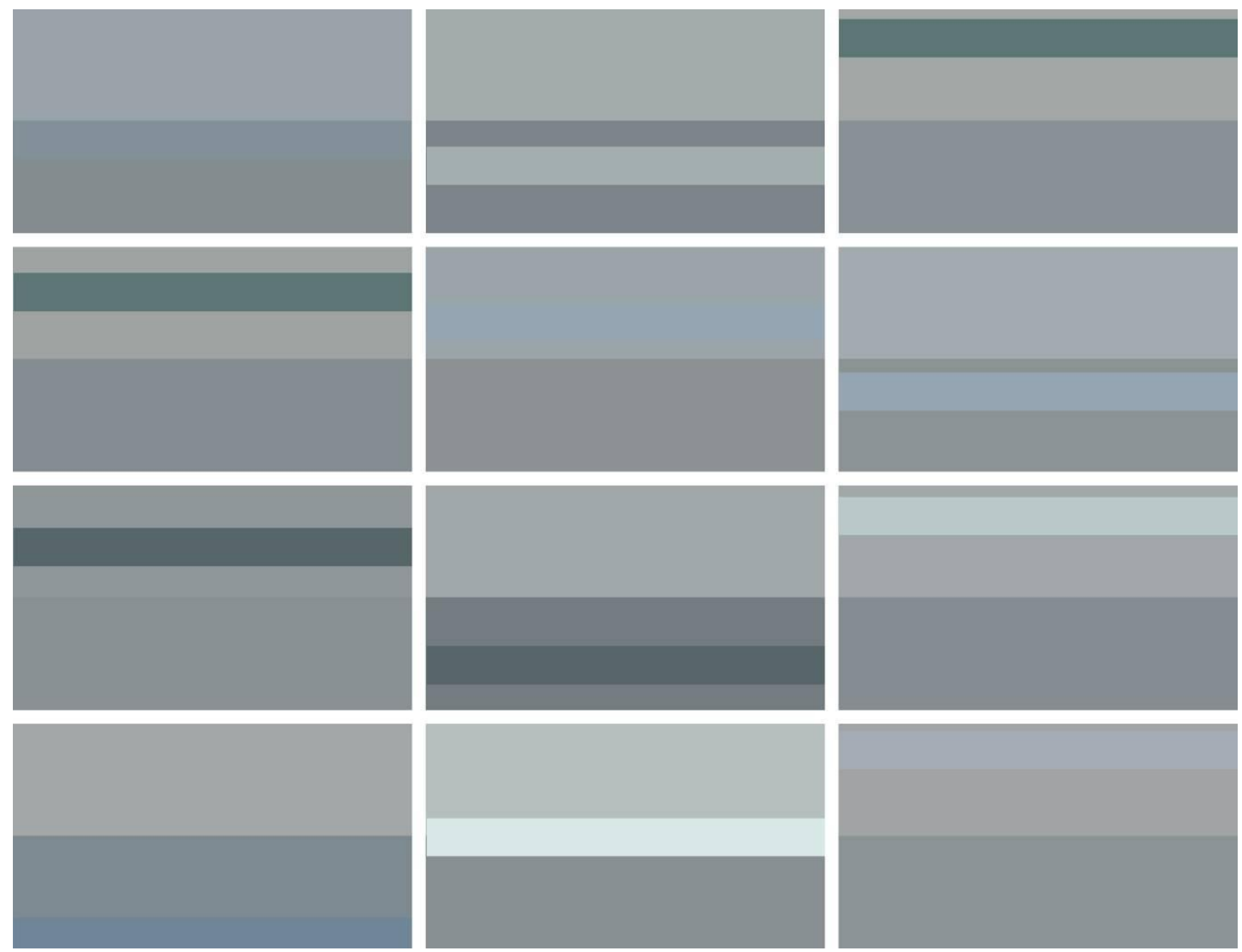

Figure 1: Sea (Variations) (2011-2015), Gareth Polmeer 